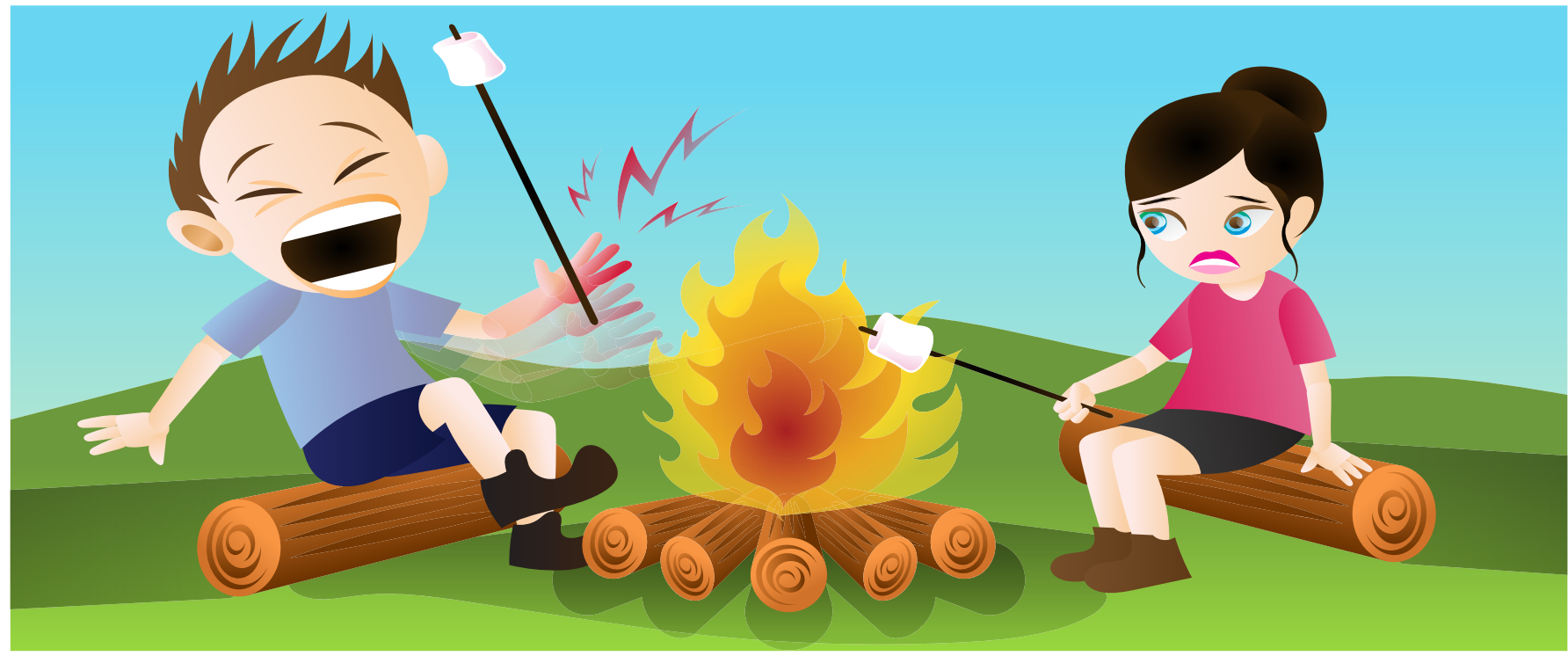

\title{
TREATING PARKINSON'S DISEASE WITH BRAIN-CONTROLLED ELECTRICAL STIMULATION
}

\section{Coralie de Hemptinne* and Nicole C. Swann*}

Department of Neurological Surgery, University of California, San Francisco, San Francisco, CA, USA

REVIEWED BY:

DARIUS

10 YEARS OLD
In this article, we discuss a treatment for a brain disorder called Parkinson's disease. People with Parkinson's disease have abnormal movements. One treatment that improves the symptoms involves sending electricity to deep parts of the brain. A problem with the treatment is determining how much electricity to send and when to send it. Without knowing these things, sometimes too much electricity is used and side effects can occur or too little stimulation is sent and the patient's symptoms do not improve. A solution to this problem would be providing feedback to the device, telling the device how bad the symptoms are at a certain time, so that the amount of electricity used can be adjusted. This way the device could send stimulation only when the patient really needs it (when they have bad symptoms). Scientists think that brain signals may make a good feedback signal for these devices. Since Parkinson's disease is a brain disorder, brain activity during symptoms may be different from when there are no symptoms.

Imagine you are playing tag with your friends. You see your friend hiding by a tree about $15 \mathrm{ft}$ away. You start running over to the tree to tag her, but she sees you coming and suddenly sprints off in the other direction toward the swing! What do you do? Should you continue running toward the tree like 
FEEDBACK SIGNAL Information that is sent back. This information can help determine if behavior or other actions need to be adjusted.

\section{FIGURE 1}

Example of feedback signal.

When the hand is too close to the fire, the fingers send a signal telling the brain they are too hot. Based on that feedback signal the brain commands the arm to move away from the fire.

you planned, and then run to the swing? Or do you change your plan and run directly to the swing? Of course, you go straight to the swing if you want to catch her!

What you did may not seem so hard, but it actually is kind of a big deal! You first made a plan to run toward the tree, but when you saw your friend change her hiding spot, you changed your plan. You adjusted your body's action based on what you saw your friend do. This is called a "feedback signal," and we use these signals all the time to control our behavior, even though we do not always realize it.

For another example of how you use feedback signals to adjust your behavior, imagine you are roasting marshmallows by a campfire. You want to get the perfect marshmallow, so you move your stick as close as you can to the fire. Suddenly, you feel your fingers heat up. You moved your hand too close! You quickly move your hand away before you even have to think about it. This is because your brain received a feedback signal from your fingers that they were getting too hot. In response to this signal, you changed your plan about how close to the fire you should get. You originally planned to move your hand closer, but now your new plan is to move your hand away! (see Figure 1).

Feedback signals are used all the time to adapt our behavior. They can also be very useful when certain parts of your body are not working well. When this happens, a doctor may use a small machine to help the broken body parts do their job, and a feedback signal can be used to tell the machine when to work. This way, the machine and feedback signal can work together with the rest of your body to make sure everything is working correctly.

Have you heard of a "pacemaker" for a heart? This is a small machine that doctors use to help someone whose heart is not working properly. If you put your ear on your parent's chest you can hear their heart beating. Do you notice how regular this beat is? This regular rhythm is very important. Your heart

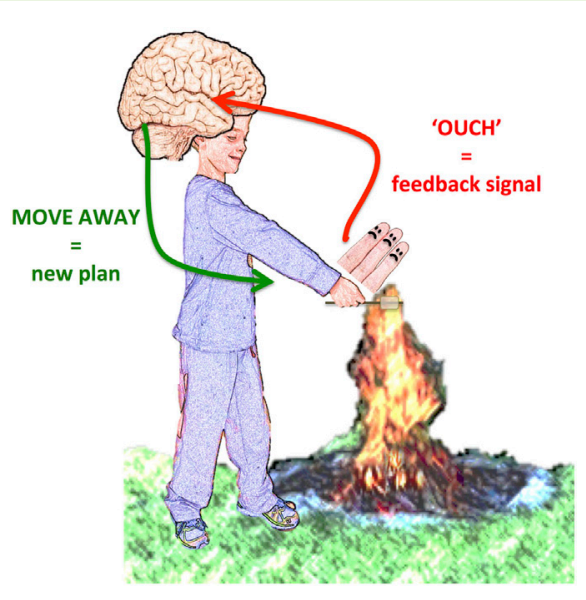


PARKINSON'S DISEASE (PD)

A brain disorder that affects movement.

\section{DEEP BRAIN} STIMULATION (DBS) A treatment for brain disorders like PD where electricity is delivered to structures deep in the brain.

\section{FIGURE 2}

Illustration of a heart pacemaker.

A. Tiny electrodes are placed in the heart and connected to a small computer placed under the skin in the chest. $\mathbf{B}$. The recording electrode is used as a microphone to record the heartbeat. That heart song is sent to the computer that calculates the speed that the heart is beating. If the heartbeat is not the correct speed, the computer sends small electrical jolts to the heart through the stimulating electrode to bring the heart back into a normal rhythm.

needs to beat regularly, with beats evenly spaced in time, so it can pump blood throughout your body. Unfortunately, some people's heartbeats beat too fast or too slow, and this can be very dangerous. One way to fix this problem is to perform a surgery to place a tiny wire (called an electrode) in the heart and connect it to a tiny computer that is placed under the skin of the chest (see Figure 2A). This pacemaker can fix the irregular beating by sending a short jolt of electricity to the heart when it is not beating at the correct speed. But how does the pacemaker know when to send the jolt? That is where a feedback signal comes in. The electrode records the heartbeat, like a microphone, and sends this heart "song" to the computer. The computer can quickly calculate the speed that the heart is beating. If the computer notices that heartbeat is too fast or too slow, it sends a jolt of electricity through the electrode (see Figure 2B). This "electrical stimulation" helps the heart rhythm return to normal. Think of this stimulation like the extra push young kids might need from their mom or dad to help them get up a tough hill when riding their bike. The electrical stimulation provides a little push to help the heartbeat get back on track.

Sometimes, it is your brain that needs the extra push to get back on track. An example of when the brain does not work correctly is Parkinson's disease (which can be shortened to: "PD”). PD is a brain disease that affects how people move. It affects mainly older people, and it can make them move very slowly and have trouble starting to move. It also can cause shaking (this is called tremor). One treatment for PD is a sort of "pacemaker for the brain." During a surgery, doctors place small electrodes deep into the brain and connect them to a tiny computer placed in the chest (see Figure 3A). This computer also contains a battery, which powers the device and allows electrical stimulation to be delivered to the deep parts of the brain through these electrodes. This electrical stimulation actually improves patient's symptoms! This treatment is called deep brain stimulation (which can be shortened to: "DBS").

A Picture of a heart pacemaker

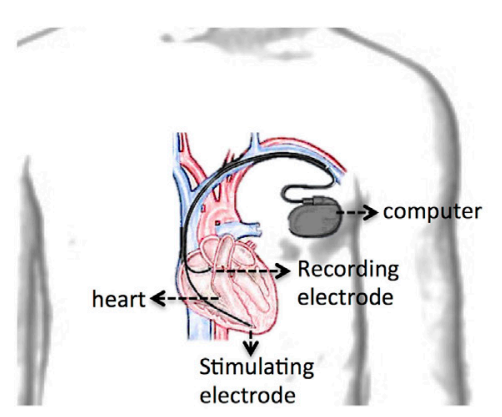

B How does it work?
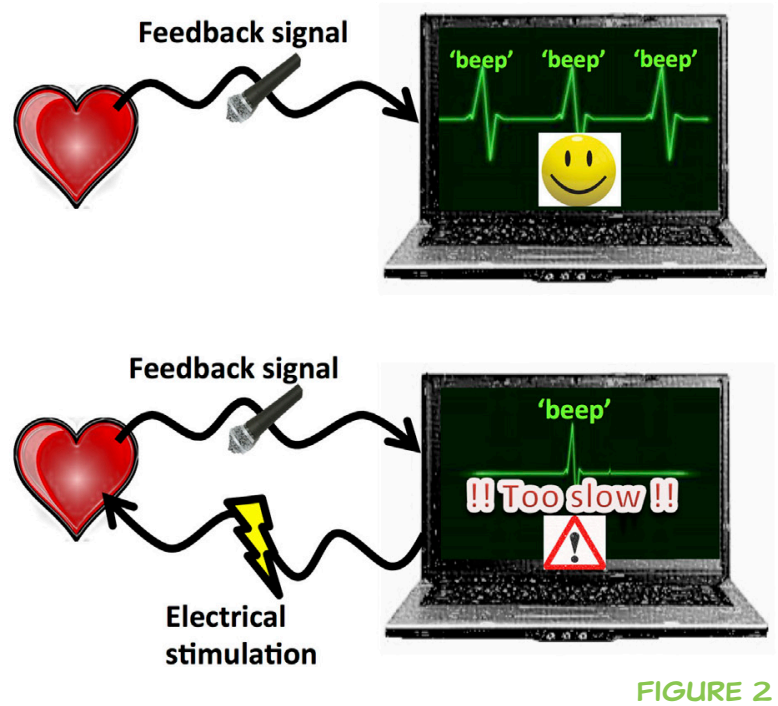
During DBS, very short rectangular pulses of current are sent to the brain (about 130 pulses per second or $130 \mathrm{~Hz}$ ). DBS current alternates between negative and positive directions, but the shape of the pulses and speed that they change direction is different than the alternating current $(\mathrm{AC})$ that comes from plugs in your wall.

Where the doctors decide to put the electrodes for DBS depends on the patient's symptoms, but for PD, usually the electrodes are lowered into part of a small group of structures in the middle of the brain called the basal ganglia (you can see a picture of this in Figure 3A).

Deep brain stimulation works really well to control the abnormal movements in many PD patients. However, it is not perfect. One problem is that DBS does not have a feedback signal to turn off stimulation. This means that the stimulation is on all the time. The problem is that patient's symptoms change throughout the day. Sometimes, they shake a lot or move very slowly, and sometimes, they feel pretty good. But, the stimulation cannot adapt to these changes because it does not have feedback about how the patient is feeling. This means that sometimes the electrical stimulation is too strong and can cause side effects and other times it is too weak and does not improve symptoms very much. Think back to the example of playing tag with your friends. Having no feedback in that situation would be like trying to chase your friends with your eyes closed. How would you know where to run? Do you think you would be very good at the game? This is the problem with DBS without feedback.

One way to improve DBS is to add a feedback signal. The best feedback signal would be one that is related to a patient's symptoms, so that stimulation could be used when the symptoms are bad and be stopped or reduced when

\section{FIGURE 3}

Illustration of a brain pacemaker (DBS).

A. Tiny electrodes are placed in the brain and connected to a small computer placed under the skin in the chest.

B. This figure shows that the amount of synchronization is much higher in PD compared to controls (people without $\mathrm{PD})$. In PD, the "brain song" is unbalanced because neurons are too synchronized.

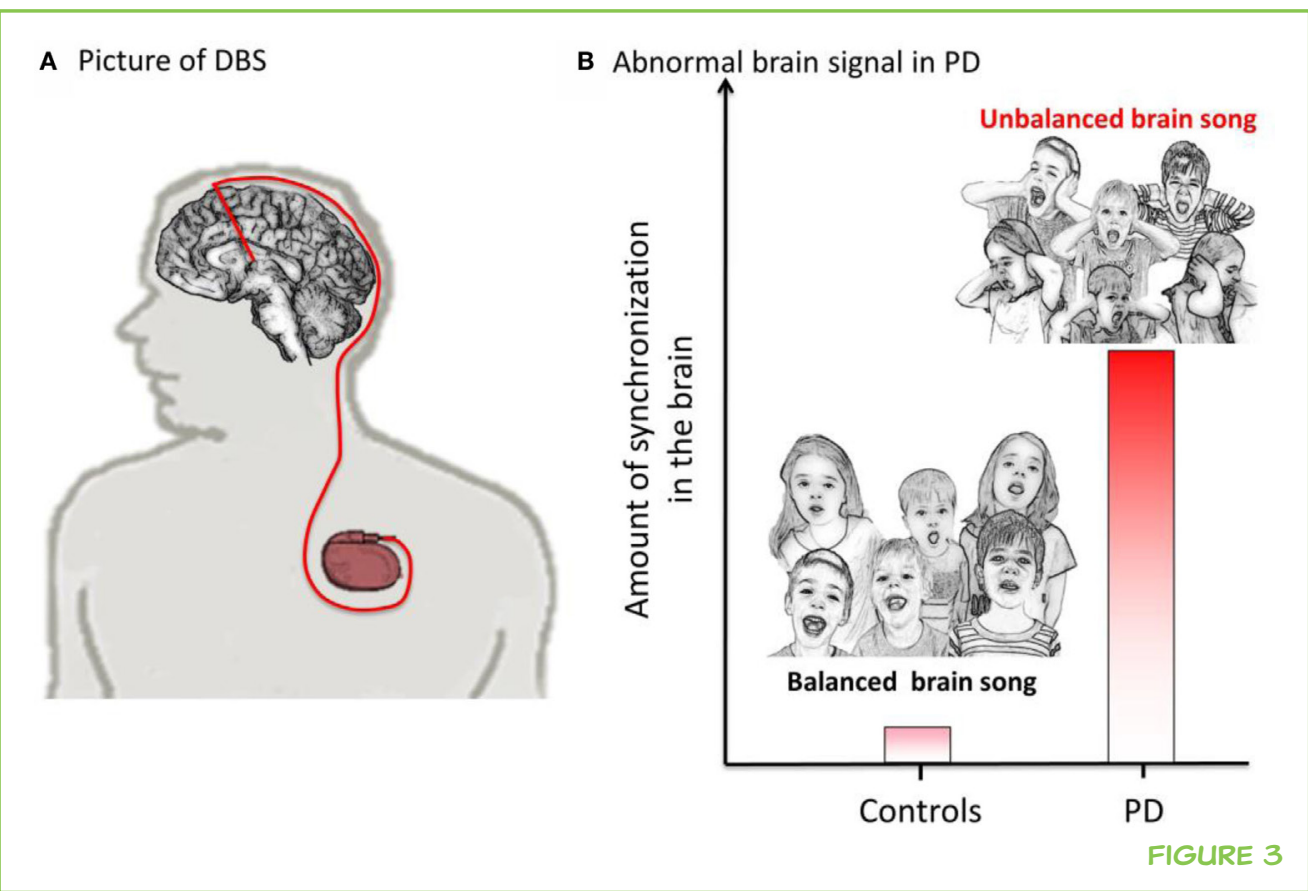


the symptoms go away. The problem is that brain activity is more complicated than heart activity, so we are not yet sure what feedback signals would work the best. Many scientists are working on that problem right now! To find the best feedback signal, they record the activity of the brain using electrodes placed in or on the patient's brain. Scientists' record brain signals when PD patients are feeling good and compare this to when the patients are feeling bad because of their symptoms. Scientists can also compare brain signal recorded in PD patients to those recorded in healthy people (they call them controls). These experiments help scientists decide on a brain signal that shows when patients are having bad symptoms, and this signal can be used as feedback to tell the DBS machine when to turn on.

Recently, using these techniques, scientists have made some important discoveries. They have found that in PD the neurons are excessively "synchronized" $[1,2]$. This means that the neurons always "sing" together, at the same time, and are unable to listen to each other. You can think of the healthy brain as being like a choir. The conductor tells the singers (called the brain cells or neurons) when to keep the same rhythm (or tempo) and tells them when they need to change tempo or be quiet. The choir singers also listen to each other to make sure that none of them sings louder than the others and that they are all responding to changes in each others tempo. This can be thought of as a "balanced choir," or balanced brain activity ("balanced brain song"). In the brain, changes in rhythms or tempo relate to changes in behavior. For example, if you want to move your arm, the rhythm of the neurons (tempo of the choir) will change, and then you will move. In PD patients, movements may be abnormal because the rhythms of the neurons are too strong, and so they do not change easily. This may cause the patient to be "stuck" or have difficulty starting to move. It is like some of the singers in the choir are singing all together at the very same time, and not listening to the conductor or other singers, when it is time to change the tempo. This small group may become louder and louder and keep the whole choir from being able to work together. It could be thought of as an "unbalanced song," unbalanced brain activity. This may be why PD patients cannot move normally. The stronger the voice or loudness the worse the PD symptoms are. You can see an example of this abnormal synchronization in Figure 3B.

SYNCHRONIZATION Occurring at the same time. In this article we discuss how brain cells can have too much synchronization in PD, meaning that their activity at each moment is too similar to one another.
This gave scientists the idea that the amount of synchronization might be a good feedback signal for DBS. Changes in the feedback signal could be used to decide when to stimulate the brain. The way this would work is very similar to the heart pacemaker. The small electrodes placed in the brain will record the brain "song," like a microphone, send this "feedback signal" to the small computer which will calculate how synchronized the neurons are and use that to decide when to change the amount of electricity sent to the brain. When the patient feels bad because synchronization is very strong, the computer will send a jolt of electricity to the brain through the small electrodes. When a patient feels good and the synchronization is normal, the stimulation will be 


\section{FIGURE 4}

Illustration of DBS using "brain song" as a

feedback signal.

The recording electrode is used as a microphone to record the brain song and sends it to the computer that calculates the amount of synchronization. If too synchronized, the brain song is unbalanced and patient is not feeling good. Then, the computer sends small electrical jolts to the brain through the stimulating electrode. Once the brain song is nice and balanced, the patient feels good and the stimulation can be turned off.

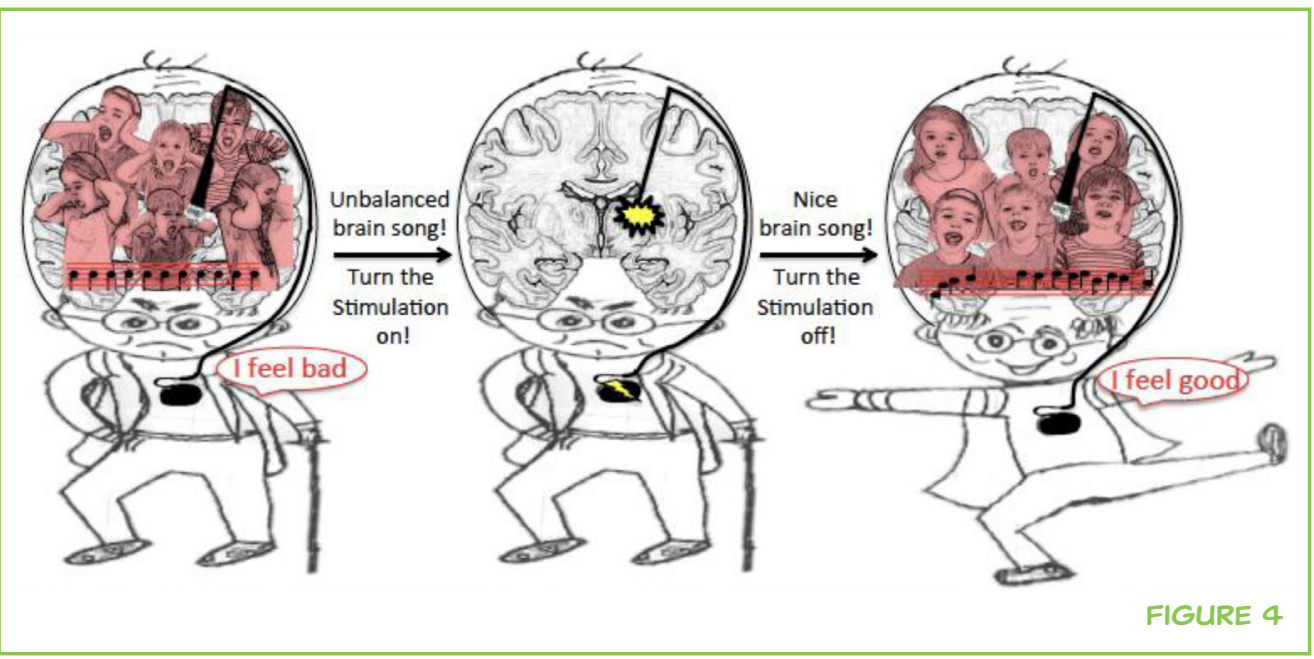

turned down or even stopped (you can see a picture of Figure 4). In this way, the symptoms can be controlled in a smarter way, which could help improve symptoms and avoid side effects. Scientists are working on testing their idea right now! More testing is still needed, but early experiments have shown that using the amount of synchronization as a feedback signal does actually help patient's symptoms [3]. This is very exciting because it means that soon PD patients will have better treatment!

\section{REFERENCES}

1. Little, S., Brown, P. 2014. The functional role of beta oscillations in Parkinson's disease. Parkinsonism Relat. Disord. 20:S44-S48. doi:10.1016/S13538020(13)70013-0

2. de Hemptinne, C., Swann, N. C., Ostrem, J. L., Ryapolova-Webb, E. S., San Luciano, M., Galifianakis, N. B., et al. 2015. Therapeutic deep brain stimulation reduces cortical phase-amplitude coupling in Parkinson's disease. Nat Neurosci. 18:779-786. doi:10.1038/nn.3997

3. Little, S., Pogosyan, A., Neal, S., Zavala, B., Zrinzo, L., Hariz, M., et al. 2013. Adaptive deep brain stimulation in advanced Parkinson disease. Ann. Neurol. 74:449-457. doi:10.1002/ana.23951

SUBMITTED: 16 February 2016; ACCEPTED: 27 July 2016;

PUBLISHED ONLINE: 12 August 2016.

EDITED BY: Robert T Knight, University of California, Berkeley, USA

CITATION: de Hemptinne C and Swann NC (2016) Treating Parkinson's Disease with Brain Controlled Electrical Stimulation. Front. Young Minds 4:10. doi:10.3389/frym.2016.00010 
CONFLICT OF INTEREST STATEMENT: UCSF has submitted two pending/provisional patents related to use of particular brain signals for closed loop DBS. Drs. NS and $\mathrm{CH}$ are included as co-inventors on these patents.

COPYRIGHT (C) 2016 de Hemptinne and Swann. This is an open-access article distributed under the terms of the Creative Commons Attribution License (CC BY). The use, distribution and reproduction in other forums is permitted, provided the original author(s) or licensor are credited and that the original publication in this journal is cited, in accordance with accepted academic practice. No use, distribution or reproduction is permitted which does not comply with these terms.

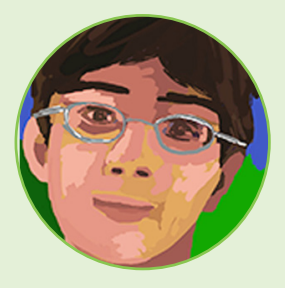

\section{REVIEWED BY}

\section{DARIUS, 10 YEARS OLD}

I am 10 years old and in fifth grade. In my free time, I enjoy reading and computer programming. As a hobby, I make useful objects and experiment with devices.

I am very interested in the environment and was one of the founders of my school's green committee. I enjoy reading about science, particularly chemistry, biology, and neuroscience.

\section{AUTHORS}

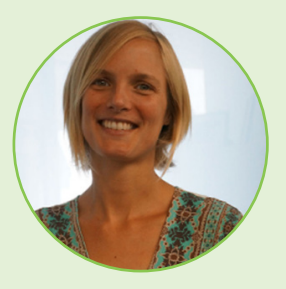

\section{CORALIE de HEMPTINNE}

How does the brain work and what happens when it does not work well? These questions have always fascinated me and motivated me to become a scientist. As a researcher at UCSF, I try to understand abnormal brain patterns of patients who suffer from Parkinson's disease, and how to use this information to improve treatments. Outside of my research, I love spending time with my family, traveling, playing tennis, and watching movies. *Coralie.Dehemptinne@ucsf.edu

\section{NICOLE C. SWANN}

I love being a scientist because I am always learning new things and can come up with creative ways to ask questions and solve problems. I study how parts of the brain work together to allow us to move our bodies, and how we are able to flexibly stop and change movements, when necessary. I also study what happens when these processes do not happen normally, which can lead to movement disorders, such as Parkinson's disease. When I am not doing science, I like to hike, swim, do yoga, run, ride my bike, and hang out with our pets: Sebastian the dog, Edinger the cat, and Odys the tortoise. *Nicole.Swann@ucsf.edu 